\title{
Cytomegalovirus (CMV) infection in HIV/AIDS patients and diagnostic values of CMV-DNA detection across different sample types
}

\author{
Min Zhao, Chuanshang Zhuo, Qinguang Li, Lijuan Liu \\ Department of Clinical Laboratory, Mengchao Hepatobiliary Hospital of Fujian Medical University/Fuzhou Infectious Diseases Hospital, Fuzhou, \\ China \\ Contributions: (I) Conception and design: M Zhao, L Liu; (II) Administrative support: Q Li, L Liu; (III) Provision of study materials or patients: M \\ Zhao; (IV) Collection and assembly of data: M Zhao; (V) Data analysis and interpretation: C Zhuo, L Liu; (VI) Manuscript writing: All authors; (VII) \\ Final approval of manuscript: All authors. \\ Correspondence to: Lijuan Liu. Department of Clinical Laboratory, Mengchao Hepatobiliary Hospital of Fujian Medical University/Fuzhou Infectious \\ Diseases Hospital, Fuzhou, China. Email: 1jliu@126.com.
}

\begin{abstract}
Background: Cytomegalovirus (CMV) is a common herpesvirus that has spread throughout the human population. It can easily cause organ damage in individuals who are immunocompromised. While many studies have examined the virology and immunology of simple CMV infection, few articles have described the unique immunological features of patients with HIV-CMV coinfection.

Methods: CMV infection was detected in 808 HIV/AIDS inpatients in our center from January 2017 to October 2019, and the relevant data from these patients were retrospectively analyzed. HIV-RNA, CD4+ T lymphocyte count, CMV-DNA, and related antibodies were measured in all patients. The positive rates of CMV-DNA in blood, urine, and cerebrospinal fluid (CSF) were compared. The positive rates between anti-CMV-immunoglobulin M (IgM) antibody and CMV-DNA in blood were compared. The correlation between immune status and CMV positive rate was analyzed based on the CD4+ T lymphocyte count.

Results: The overall positive rate of CMV infection in HIV/AIDS patients was 29.05\%. The positive rate of CMV-DNA in urine, blood, and CSF samples was $25.27 \%, 26.01 \%$, and $5.70 \%$, respectively, and showed no significant difference between urine and blood. However, plasma CMV-IgM antibody level was significantly different between the urine and blood. The absolute CD4+ T lymphocyte count and the HIVRNA level were significantly different between the CMV-infected group and the non-CMV infected group. Conclusions: Low CD4+ T lymphocyte count and high HIV-1 viral load are risk factors for CMV infection in HIV/AIDS patients. Detection of urine or plasma CMV-DNA by using real-time fluorescence quantitative polymerase chain reaction (PCR) is highly valuable in screening CMV infection in HIV/AIDS patients, while detection of blood CMV IgG and CMV IgM levels has limited clinical value.
\end{abstract}

Keywords: Cytomegalovirus (CMV); AIDS; CD4+ T lymphocytes; HIV-RNA quantification

Submitted Apr 29, 2020. Accepted for publication Jul 29, 2020.

doi: 10.21037/apm-20-1352

View this article at: http://dx.doi.org/10.21037/apm-20-1352

\section{Introduction}

Cytomegalovirus (CMV) is a common herpesvirus that is widespread across human populations. CMV infection usually does not cause symptoms and mainly affects the salivary glands, kidneys, and other organs. However, viral replication can occur in immunocompromised patients and may contribute to the damage to organs and their functions. Opportunistic infections are more frequent and severe in HIV/AIDS patients. CMV virus infection is common in these patients and can affect multiple organs/systems 
including the eyes, lungs, nervous system, and digestive system. Many studies have explored the virological and immunological characteristics of simple CMV infection (1), especially those found in women and children. The immunological features of CMV infection, however, are quite unique in already immunocompromised HIV/AIDS patients. There are differences in clinical characteristics, treatment measures, prognostic factors between HIV patients with $\mathrm{CMV}$ infection and those with $\mathrm{CMV}$ infection alone (2). The guideline of China recommended that immediately antiviral therapy of CMV and ART are needed in those HIV/AIDS patients with complications (retinitis, pneumonia, CMV encephalitis, enteritis, etc.) when CMV infection is identified. Because of the non-specificity of clinical symptoms caused by CMV infection, laboratory examination is the main basis for the diagnosis of CMV infection. The most two widely used clinical methods are CMV virus replication and serum immunological methods including the detection of CMV IgG, CMV IgM and CMV antigen PP65 (2) In patients with impaired immune function, the production of CMV antibody is weakened or delayed, which may lead to false negative and increase the rate of missed diagnosis, therefor PCR detection of CMVDNA has largely become the standard method for diagnosis of CMV infection and monitoring of treatment (3). Daisuke Mizushima et al. reported that plasma CMV-DNA PCR has important value in the diagnosis for both CMV retinitis and all CMV-EOD in patients with advanced HIV-1 infection (4). CMV-DNA PCR can be detected in a variety of sample types such as plasma, urine, cerebrospinal fluid, aqueous humor, feces, etc. (5). However, few articles have analyzed and discussed the significance and value of CMVDNA PCR detection in samples other than plasma. In the present study we retrospectively analyzed the laboratory tests (including CMV-DNA, CMV antibody, $\mathrm{CD}^{+}{ }^{+} \mathrm{T}$ lymphocyte count, HIV viral load, etc.) in 808 HIV/AIDS patients who were treated in our center from 2017 to 2019 to understand the CMV coinfection and the strengths and weaknesses of several detection methods. We present the following article/case in accordance with the MDAR reporting checklist (available at http://dx.doi.org/10.21037/ apm-20-1352).

\section{Methods}

\section{Subjects}

A total of 808 HIV/AIDS inpatients admitted to our center between January 2017 and October 2019 were enrolled. HIV-RNA, $\mathrm{CD}^{+}{ }^{+} \mathrm{T}$ lymphocyte count, CMV-DNA, and related antibodies were measured in each patient. The diagnosis of HIV infection was based on the HIV/AIDS Diagnosis and Treatment Guidelines (third edition) (6), and all patients were confirmed as HIV infection by the Fuzhou Municipal Centers for Disease Control (CDC) or the local CDC which treated the patient. Diagnosis of CMV infection was based on the following criteria: (I) CMV-DNA positive in plasma, alveolar lavage fluid, urine, cerebrospinal fluid (CSF), and/or other body fluids; (II) serum CMV-immunoglobulin $\mathrm{M}(\mathrm{Ig} M)$ positive; (III) an ophthalmological diagnosis of CMV retinitis; (IV) CMV pneumonia mainly manifesting as fever, cough, phlegm, and chest tightness; CMV-DNA positive in alveolar lavage fluid; (V) CMV enteritis or esophagitis mainly manifesting as dysphagia/swallowing pain, diarrhea, or abdominal pain, and effective diagnostic anti-CMV treatment; (VI) CMV encephalitis manifesting as nervous system symptoms and CMV-DNA positive in CSF or brain tissue; (VII) CMV hepatitis manifesting as fever, abnormal liver function, and discomfort in the liver area, and CMV-DNA positive in liver biopsy. A diagnosis of CMV infection was made if any of the above criteria except item (II) was met or if item (II) plus any other criterion was met (7).

All procedures performed in this study involving human participants were in accordance with the Declaration of Helsinki (as revised in 2013). The study was approved by the medical ethics committee of our center (approval No. KS2019-070-01). The data are anonymous, and the requirement for informed consent was therefore waived.

\section{Inclusion and exclusion}

Inclusion criteria: patients with HIV/AIDS who first visited Mengchao Hepatobiliary Hospital of Fujian Medical University and completed the detection of HIVRNA,CMV-DNA, CMV-IgG antibody, CMV-IgM antibody and $\mathrm{CD}^{+} \mathrm{T}$ lymphocytes within 14 days. Exclude HIV/AIDS cases that cannot complete the above testing items due to insufficient sample size.

\section{Reagents and equipment}

\section{HIV-RNA quantification}

Fluorescent quantitative real-time polymerase chain reaction (PCR) (FQ-PCR) was performed on the Mx3000p QPCR system (Agilent, USA) by using the HIV-RNA 
quantification kit produced by QiaGen (Shenzhen, China).

\section{$\mathrm{CD}^{+} \mathrm{T}$ lymphocyte counting}

The instrument used was the FACSCalibur flow cytometer (BD Biosciences, USA), and the reagent kit used was BD Multitest CD3/CD4/CD8/CD45 (BD Biosciences, USA).

\section{CMV-DNA quantification}

FQ-PCR was performed on the Mx3000p QPCR system (Agilent, USA) to detect the CMV-DNA levels in plasma, urine, and CSF. The kit used was produced by Sansure Biotech (Hunan, China).

\section{CMV antibody test}

Chemiluminescence immunoassay was performed to detect anti-CMV-IgG and IgM antibodies on the Cobas e601 analyzer (Roche Diagnostics, Germany) with the supporting kits (Roche Diagnostics, Germany).

\section{Study methods}

\section{Nucleic acid detection}

After the HIV/AIDS patients were admitted to our hospital, $3 \mathrm{~mL}$ of fasting ethylenediaminetetraacetic acid (EDTA)anticoagulated whole blood specimen was collected and then centrifuged at $3,000 \mathrm{r} / \mathrm{min}$ for 5 minutes to harvest $200 \mu \mathrm{L}$ of plasma for HIV-RNA and CMV-DNA detection. In all patients, $5 \mathrm{~mL}$ of urine specimen was collected in the morning and mixed thoroughly, and then $200 \mu \mathrm{L}$ was harvested for CMV-DNA detection. For patients with neurological symptoms, $1 \mathrm{~mL}$ of CSF was obtained for CMV-DNA detection. According to the detection limit and positive judgment standard of CMV-DNA kit and HIVRNA kit. The specimens were considered positive if the CMV-DNA value was above 400 copies/mL, or if the HIVRNA level was above 500 copies $/ \mathrm{mL}$.

\section{Detection of T-lymphocyte subsets}

In the HIV/AIDS patients, $3 \mathrm{~mL}$ of EDTA-anticoagulated fasting whole blood specimen was collected at admission and then mixed thoroughly for T-lymphocyte subset detection on a BD FACSCalibur flow cytometer using the ancillary reagents.

\section{Detection of immune antibodies}

In the HIV/AIDS patients, $3 \mathrm{~mL}$ of fasting blood specimen was collected at admission, centrifuged at 3,000 r/min for 5 minutes in a serum tube with gel separator, and then tested on the machine.

All the above tests were carried out strictly in accordance with the reagent instructions in the manufacturer's manual and the standard operating procedures of the instruments.

\section{Statistical analysis}

Statistical analysis was performed using SPSS 21.0 software. The normally distributed measurement data are presented using mean \pm standard deviation $(\bar{x} \pm S D)$, and nonnormally distributed data are expressed as median (25-75 percentiles). The count data are expressed in percentages and rates. The comparison of the non-normally distributed measurement data between two groups was performed by using a non-parametric rank sum test, whereas the count data were compared using the Chi-square test. A P value of $<0.05$ was considered statistically significant.

\section{Results}

\section{General data}

The general data of 808 HIV/AIDS patients are summarized in Table 1. The gender and age showed no significant difference between the CMV group and nonCMV group. The absolute CD4 count in the CMV-infected group was significantly lower than that in the CMVuninfected group $(\mathrm{Z}=-8.87, \mathrm{P}<0.001)$, and the HIV-RNA level was significantly higher in the $C M V$-infected group than in the non-CMV infected group $(\mathrm{Z}=-3.207, \mathrm{P}<0.05)$ (Table 1).

\section{Positive rates of CMV-DNA, CMV-IgG, and CMV-IgM}

The overall positive rate of CMV-DNA was $29.08 \%$ (235/808); specifically, it was $5.70 \%(13 / 228)$ in CSF $26.01 \%(77 / 296)$ in plasma, and $25.75 \%(180 / 699)$ in urine. The positive rate of CMV-IgG was $99.8 \%$ (806/808), and the positive rate of CMV-IgM was $10.40 \%$ (84/808).

\section{Correlation between CMV infection andCD $4^{+} \mathrm{T}$ lymphocyte count}

After grouping the $\mathrm{CD}^{+} \mathrm{T}$ lymphocyte count, we found that the proportion of patients infected with cytomegalovirus at low frequency of $\mathrm{CD}^{+} \mathrm{T}$ lymphocyte was greater than that of non-CMV infected patients. The incidence of $\mathrm{CMV}$ infection increased with the decline of 
Table 1 General data of 823 HIV/AIDS patients

\begin{tabular}{|c|c|c|c|c|}
\hline Clinical features & CMV-infected group & CMV-uninfected group & Statistics & $P$ value \\
\hline Male & $197(83.83)$ & $454(79.23)$ & & \\
\hline Female & $38(16.17)$ & $119(20.77)$ & & \\
\hline Age (years, $\bar{x} \pm S D$ ) & $38.68 \pm 12.04$ & $37.68 \pm 11.76$ & $t=1.08$ & $>0.05$ \\
\hline HIV-RNA level (log 10 HIV RNA copies/mL) & $5.73(4.66-6.51)$ & $5.45(3.95-6.29)$ & $Z=-3.207$ & 0.001 \\
\hline CMV-IgM positive rate, $\mathrm{n}(\%)$ & $37(15.74)$ & $47(8.20)$ & $c^{2}=10.18$ & 0.002 \\
\hline
\end{tabular}

Table 2 Distribution of CD4 count in CMV-infected group and the CMV-uninfected group

\begin{tabular}{|c|c|c|c|c|c|c|c|}
\hline Group & $\mathrm{n}$ & \multicolumn{4}{|c|}{ 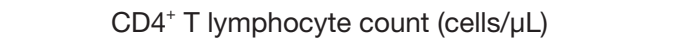 } & Statistics & $P$ value \\
\hline CMV-infected group & 235 & 181 & 30 & 14 & 10 & $Z=-8.94$ & $<0.001$ \\
\hline CMV-uninfected group & 573 & 265 & 57 & 97 & 154 & & \\
\hline
\end{tabular}

CMV, cytomegalovirus.

Table 3 Comparisons of the results of plasma CMV-DNA detection and urine CMV-DNA detection with that of plasma anti-CMV-IgM antibody detection

\begin{tabular}{|c|c|c|c|}
\hline Item & Plasma CMV-IgM positive & Plasma lgM negative & $P$ value \\
\hline Plasma CMV-DNA negative & 13 & 129 & \\
\hline Urine CMV-DNA positive & 5 & 43 & 0.002 \\
\hline Urine CMV-DNA negative & 18 & 132 & \\
\hline
\end{tabular}

$\mathrm{CMV}$, cytomegalovirus.

CD4 count (Table 2).

\section{Detection of CMV-DNA in different samples}

Of these 808 patients, 198 patients also received tests for plasma and urine CMV-DNA and plasma anti-CMV-IgG and CMV-IgM antibodies. By using the Chi-square analysis for paired data, we performed pairwise comparisons of urine CMV-DNA and plasma CMV-DNA with plasma CMVIgM antibody, respectively. It was found that the results of urine and plasma CMV-DNA detection significantly differed from that of plasma CMV-IgG antibody assay $(\mathrm{P}<0.001)$, whereas the result of plasma CMV-DNA detection was not significantly different from that of urine
CMV-DNA detection $(\mathrm{P}>0.05)$ (Tables 3,4).

\section{Discussion}

$\mathrm{CMV}$ is a member of the $\beta$-herpes virus group and is characterized by its strict species specificity and widespread incidence in human populations. CMV seroprevalence is about $85 \%$ in children and up to $95 \%$ in adults. In our current study, the positive rate of CMV-IgG reached $99.8 \%$. $\mathrm{CMV}$ is latent in most cases, but in immunocompromised individuals, the virus replicates exponentially and spreads throughout the body with the blood, causing CMV viremia and even organic CMV disease (8). CMV infection is one of the common opportunistic infections in HIV/AIDS 
Table 4 Comparisons of the detection results of plasma and urine CMV-DNA

\begin{tabular}{lccc}
\hline Item & Urine CMV-DNA positive & Urine CMV-DNA negative & P value \\
\hline Plasma CMV-DNA positive & 26 & 30 & 0.424 \\
Plasma CMV-DNA negative & 22 & 120 \\
\hline
\end{tabular}

CMV, cytomegalovirus.

patients. $\mathrm{CD}^{+} \mathrm{T}$ lymphocytes are the target cells of HIV virus, and their counts can often reflect the course of AIDS and may also be used as an indicator for evaluating the immune status of AIDS patients. This study analyzed the CMV infection, CD4 count, and HIV-RNA level in 808 patients with HIV/AIDS. We found that the positive rate of CMV in AIDS patients increased with the decrease of CD4 count and with the increase of HIV viral load. Also in our current study, up to $77.02 \%$ of $\mathrm{CMV}$-positive patients had a CD 4 count of $<50$ cells $/ \mu \mathrm{L}$, suggesting that CD 4 $<50$ cells $/ \mu \mathrm{L}$ is a risk factor for HIV-CMV coinfection, which is consistent with the finding of Deng et al. (9). The quantitative level of HIV-RNA in CMV infected group was higher than that in CMV uninfected group, which indirectly suggested that high levels of HIV-RNA viral load was another risk factor of CMV infection in HIV/AIDS patients .Therefore, It is recommended that patients with HIV/ AIDS should initiate ART treatment as soon as possible to promote immune reconstitution to prevent opportunistic infections and screening for HCMV is essential for HIV/ AIDS patients with a CD4 count of $<50$ cells/ $\mu \mathrm{L}$ (2).

We also evaluated the values of viral nucleic acid assays and immunological methods in the clinical detection of CMV infection. Studies in China and internationally have shown that CMV-DNA appears earlier than the clinical symptoms and serological reactions of CMV infections. FQ-PCR is currently the most accurate and rapid microbial quantification method and is able to overcome some problems of traditional PCR (e.g., amplification product contamination and non-quantification) (10). In our current study, the positive rate of CMV-DNA was 5.70\% (13/228) in the CSF samples of 228 patients with neurological symptoms, which was much lower than that of in plasma and urine samples, which might be explained by the bloodbrain barrier and organ susceptibility. The anti-CMV$\operatorname{IgM}$ antibody is often used as a marker of active viral infection; however, the positive rate of the anti-CMVIgM antibody was only $10.40 \%(84 / 808)$ in our HIV/AIDS patients, which was lower than the positive rate of CMV infection reported in the non-HIV/AIDS populations
(11). In addition, its positive rate had poor agreement with the results of nucleic acid detection, which might be due to the weakened immune system or due to the delayed generation of IgM antibodies in HIV/AIDS patients. Therefore, detection of CMV-IgM antibody has a limited role in HCMV screening in HIV/AIDS patients. Moreover, the positive rate of CMV infection in 808 patients was $29.05 \%(235 / 808)$ in our current study, which is slightly higher than the $21.85 \%$ reported by Li et al., and may be due to the greater variety of samples (including plasma, urine, and CSF) collected in this study (12). The positive rate of CMV-DNA was $25.57 \%$ in urine and $26.01 \%$ in plasma, the difference was not statistically significant. Therefore, we recommend that CMV-DNA screening in plasma and urine should be performed when the $\mathrm{CD}^{+} \mathrm{T}$ lymphocyte count is less than 200 cells/ $\mu \mathrm{L}$, especially when $<50$ cells $/ \mu \mathrm{L}$; in addition, detection of CMV-DNA in CSF is required if obvious neurological symptoms are present.

\section{Conclusions}

In conclusion, low $\mathrm{CD}^{+} \mathrm{T}$ lymphocyte count and high HIV-1 viral load are risk factors for CMV infection in HIV/ AIDS patients. Detection of urine or plasma CMV-DNA by FQ-PCR is highly valuable in screening CMV infection in HIV/AIDS patients, while detection of blood CMV IgG and CMV IgM levels has limited clinical value. Blood or urine CMV-DNA screening is recommended for AIDS patients to prevent and diagnose CMV infection early and improve their quality of life.

\section{Acknowledgments}

Funding: Sponsored by Key Clinical Specialty Discipline Construction Program of Fujian, P.R.C.

\section{Footnote}

Reporting Checklist: The authors have completed the MDAR reporting checklist. Available at http://dx.doi.org/10.21037/ 
apm-20-1352

Data Sharing Statement: Available at http://dx.doi. org/10.21037/apm-20-1352

Conflicts of Interest: All authors have completed the ICMJE uniform disclosure form (available at http://dx.doi. org/10.21037/apm-20-1352). The authors have no conflicts of interest to declare.

Ethical Statement: The authors are accountable for all aspects of the work in ensuring that questions related to the accuracy or integrity of any part of the work are appropriately investigated and resolved. All procedures performed in this study involving human participants were in accordance with the Declaration of Helsinki (as revised in 2013). The study was approved by the medical ethics committee of our center (approval No. KS2019-070-01). The data are anonymous, and the requirement for informed consent was therefore waived.

Open Access Statement: This is an Open Access article distributed in accordance with the Creative Commons Attribution-NonCommercial-NoDerivs 4.0 International License (CC BY-NC-ND 4.0), which permits the noncommercial replication and distribution of the article with the strict proviso that no changes or edits are made and the original work is properly cited (including links to both the formal publication through the relevant DOI and the license). See: https://creativecommons.org/licenses/by-nc-nd/4.0/.

\section{References}

1. Yu X, Tong M, He G. Effects of cytomegalovirus infection on regulatory immune cells in pregnant women Chinese. Journal of Nosocomiology.2017;27:2103-6.

2. The National Science and Technology Major Project AIDS opportunistic infection Research Group during the 13th five-year Plan. Expert consensus on clinical diagnosis and treatment of AIDS complicated with cytomegalovirus disease [J/OL]. Journal of Southwest University (Natural Science Edition): 1-17 [2020-07-23].

3. Hodowanec AC, Pikis A, Komatsu TE, et al. Treatment and Prevention of CMV Disease in Transplant Recipients: Current Knowledge and Future Perspectives. J Clin Pharmacol 2019;59:784-98.

4. Mizushima D, Nishijima T, Yashiro S, et al. Diagnostic utility of quantitative plasma cytomegalovirus DNA PCR for cytomegalovirus end-organ diseases in patients with HIV-1 infection. J Acquir Immune Defic Syndr 2015;68:140-6.

5. Michaelides A, Liolios L, Glare EM, et al. Increased human cytomegalovirus (HCMV) DNA load in peripheral blood leukocytes after lung transplantation correlates with HCMV pneumonitis. Transplantation 2001;72:141-7.

6. The infection of neurology, AIDS group of Chinese medical association. HIV/AIDS diagnosis and treatment guidelines (third edition). Chinese Journal of Infectious Diseases 2015;(10):577-93.

7. Corrales I, Giménez E, Solano C, et al. Incidence and dynamics of active cytomegalovirus infection in allogeneic stem cell transplant patients according to single nucleotide polymorphisms in donor and recipient CCR5, MCP-1, IL-10, and TLR9 genes. J Med Virol 2015;87:248-55.

8. Tagarro A, Del Valle R, Dominguez-Rodríguez S, et al. Growth Patterns in Children With Congenital Cytomegalovirus Infection. Pediatr Infect Dis J 2019;38:1230-5.

9. Deng X, Liu J, Zhang M, et al. Analysis of virological and immunological characteristics of HIV/AIDS combined with cytomegalovirus infection. Chinese Journal of Hospital Infection 2019;29:2241-6.

10. Kawano Y, Kawada J, Kamya Y, et al. Analysis of circulating human and viral microRNA sin patients with congenital cytomegalovirus infection. J Perinatol 2016;36:1101-5.

11. Li L, Gao S, Zhang T, et al. Comparison of DNA detection and IgM detection of human cytomegalovirus infection and discussion of their combined application value. Chinese Journal of Experimental Diagnostics 2015;(1):78-80.

12. Li X, Cao L, Yu C, et al. Study on the infection of cytomegalovirus in AIDS patients. Modern Preventive Medicine 2012;39:2278-9.

(English Language Editor: J. Gray)

Cite this article as: Zhao M, Zhuo C, Li Q, Liu L. Cytomegalovirus (CMV) infection in HIV/AIDS patients and diagnostic values of CMV-DNA detection across different sample types. Ann Palliat Med 2020;9(5):2710-2715. doi: 10.21037/ apm-20-1352 